\title{
Recent Advances in Chemotherapy and Surgery for Colorectal Liver Metastases
}

\author{
Guillaume Passot $^{\mathrm{a}} \quad$ Olivier Soubrane $^{\mathrm{b}} \quad$ Felice Giuliante $^{c}$ \\ Giuseppe Zimmittic Diane Goéréd Suguru Yamashita ${ }^{a}$ \\ Jean-Nicolas Vauthey ${ }^{a}$
}

aDepartment of Surgical Oncology, The University of Texas MD Anderson Cancer Center, Houston, Tex., USA, bDepartment of HPB Surgery, Beaujon Hospital, Clichy, France, ${ }^{c}$ Hepato-Biliary Surgery Unit, Foundation Policlinico Universitario Agostino Gemelli, Catholic University of the Sacred Heart, Rome, Italy, dDepartment of Surgical Oncology, Gustave Roussy, Villejuif, France

\section{Key Words}

Chemotherapy-related liver injuries · Colorectal cancer · Colorectal liver metastases ·

Hepatic arterial infusion of chemotherapy $\cdot R A S$ mutation status

\begin{abstract}
Background: The liver is the most common site of metastases for colorectal cancer, and combined resection with systemic chemotherapy is the most effective strategy for survival. The aim of this article is to provide a comprehensive summary on four hot topics related to chemotherapy and surgery for colorectal liver metastases (CLM), namely: (1) chemotherapyrelated liver injuries: prediction and impact, (2) surgery for initially unresectable CLM, (3) the emerging role of RAS mutations, and (4) the role of hepatic arterial infusion of chemotherapy (HAIC). Summary and Key Messages: (1) The use of chemotherapy before liver resection for CLM leads to drug-specific hepatic toxicity, which negatively impacts posthepatectomy outcomes. (2) Curative liver resection of initially unresectable CLM following conversion chemotherapy should be attempted whenever possible, provided that a safe future liver remnant volume is achieved. (3) For CLM, RAS mutation status is needed to guide the use of targeted chemotherapy with anti-epithelial growth factor receptor (EGFR) agents, and is a major prognostic factor that may contribute to optimize surgical strategy. (4) HAIC agents increase the rate of objective response and the rate of complete pathological response.
\end{abstract}

Copyright $@ 2016$ S. Karger AG, Basel 


\section{Introduction}

The liver is the most common site of metastases for metastatic colorectal cancer (mCRC) [1]. When feasible, hepatic resection combined with systemic chemotherapy remains the most effective strategy to improve survival $[2,3]$. Advances in surgical techniques and perioperative care have improved the safety of major liver resection [4]. Furthermore, with modern chemotherapy, up to $25 \%$ of patients presenting with stage IV disease can still undergo resection [2]. One of the main challenges in the management of patients with colorectal liver metastases (CLM) is to identify those who can derive significant benefit from hepatic resection. Systemic preoperative chemotherapy is proposed either for resectable CLM to evaluate tumor response and increase the disease free survival (DFS) [5], or to convert unresectable to resectable CLM. However, prolonged preoperative chemotherapy increases the perioperative risk for patients who undergo liver resection [6]. Despite, perioperative systemic chemotherapy, more than $60 \%$ of patients who undergo liver resection for CLM will suffer recurrence in the liver. To decrease the risk of hepatic recurrence, hepatic arterial infusion of chemotherapy (HAIC) has also been proposed.

The aim of this article is to provide a summary on four topics relevant to chemotherapy and surgery for CLM: (1) chemotherapy-related liver injuries, (2) surgery for initially unresectable CLM, (3) the emerging role of RAS mutations, and (4) the role of HAIC.

\section{Chemotherapy-Related Liver Injuries: Prediction and Impact}

Chemotherapy is used prior to resection of mCRC of the liver to convert borderline or unresectable disease, but also increasingly to treat patients preoperatively to improve the selection and outcome of resectable metastases. This wide use of chemotherapy before surgical resection is associated with injury to the normal liver parenchyma. 5-fluorouracil (5FU) and folinic acid are used in association with either oxaliplatin as "FOLFOX" or irinotecan as "FOLFIRI." The main histological lesions observed are steatosis and steatohepatitis with FOLFIRI, sinusoidal obstruction syndrome (SOS) and nodular regenerative hyperplasia (NRH) with FOLFOX, respectively. The presence of these two main entities may be predicted before liver resection.

Oxaliplatin-induced SOS occurs in between 50 to $80 \%$ of patients, half of which have moderate to severe forms (grade 2 and 3), thereby increasing morbidity after major liver resection without effect on postoperative mortality [7]. The most severe form of oxaliplatin toxicity is NRH, which can lead to portal hypertension. SOS is detected by non-invasive procedures, but can be further defined and graded by histologic analysis of a liver biopsy. The Aspartate aminotransferase to platelet ratio index (APRI) score is the aspartate aminotransferase to platelet count ratio. In patients treated with oxaliplatin, an APRI score $>0.36$ is predictive of severe SOS and is associated with increased morbidity after major hepatectomy [8]. The severity of SOS also correlates with spleen volume and, inversely, with platelet count [9]. SOS lesions are partially prevented by bevacizumab.

Irinotecan is responsible for fatty liver disease, i.e. steatosis and steatohepatitis. While steatosis increases blood loss and morbidity after hepatectomy, steatohepatitis increases mortality and impairs liver regeneration [10]. Steatohepatitis is more frequent in cases of obesity and diabetes. While magnetic resonance imaging is the method of choice for the detection of steatosis, this imaging modality is not of clinical use to evaluate steatohepatitis. The diagnosis of steatohepatitis still relies on detailed histology of non-alcoholic steatohepatitis. 
In conclusion, the use of chemotherapy before liver resection for CLM leads to drugspecific hepatic toxicity, which negatively impacts posthepatectomy outcomes. Liver injury should be detected to adjust the surgical strategy. When liver injury is expected, the interval between chemotherapy and surgery should be increased for at least five weeks to minimize surgical complications.

\section{Surgery in Initially Unresectable Patients}

The definition of unresectability of CLM is conventionally based on two main criteria: (1) a technical one, consisting of the inability to obtain complete resection of all lesions, leaving at least $20-25 \%$ of residual liver volume with adequate inflow and outflow; (2) a biological one, mainly depending on CLM characteristics (number, diameter and location) [11,12], for which no standard definition is currently available. Consequently, in practice unresectability of CLM is determined by a multidisciplinary team on a per patient basis. It may vary among different hepatobiliary surgical units, accounting for differences in prognosis among different published series. The combined use of chemotherapy and surgery has contributed to an increase in resectability and survival. This is based on the effective "conversion" chemotherapy agents (oxaliplatin and irinotecan) in combination with molecular targeted agents (bevacizumab and cetuximab), in association with liver remodeling strategies including portal vein ligation or embolization [13]. Associating Liver Partition and Portal Vein Ligation for Staged Hepatectomy [14], which represents a new strategy, currently remains investigational due to associated high morbidity and mortality.

In the era of a multimodal approach to CLM, the definition of unresectability is evolving with the use of effective chemotherapy agents, in association with liver volume modulation strategies and parenchymal sparing techniques [15]. The strongest predictor of both disease free and overall survival is the pattern of response to preoperative chemotherapy. Tumor progression during preoperative chemotherapy has been reported both as a negative prognostic factor [16] as well as a predictor of inability to complete two-stage hepatectomy [17]. Thus, the response to chemotherapy is a reliable surrogate marker of tumor biology and aggressiveness. Despite the low perioperative risk, liver resection should be carefully considered in patients with a lack of response to preoperative chemotherapy.

Patients with initially unresectable CLM often receive long duration preoperative chemotherapy and undergo highly complex surgical procedures. These two factors have been associated with poor outcome following liver resection $[18,19]$. Cauchy et al. [18] reported higher rates of morbidity and mortality due to the liver injury related to chemotherapy among initially unresectable CLM patients receiving more than 12 cycles of chemotherapy prior to portal vein embolization and liver resection.

Regarding oncologic outcomes, variable survival rates have been reported, mainly due to resectability-related patient selection criteria [20-22]. Analysis of survival and prognostic factors show that despite recent reports questioning the prognostic value of surgical margin status, R0 resection (a microscopically negative resection margin) still remains an important determinant of survival $[23,24]$. Positive resection margins containing tumor are associated with a twofold increase in liver recurrence compared to those having R0 resection.

In conclusion, curative liver resection of initially unresectable CLM following conversion chemotherapy should be attempted whenever possible, regardless of the initial tumor load, preoperative chemotherapy duration and the extent of liver resection provided there is some hepatic parenchymal sparing. Tumor response to preoperative chemotherapy, which may be considered a surrogate of tumor biology and aggressiveness, is the strongest prognostic fac- 
tor and may help select patients benefitting the most from resection of initially unresectable CLM.

\section{Evaluation and Prognosis of Resected Patients: the Emerging Role of RAS Mutations}

For mCRC, RAS mutation status is the most clinically relevant molecular marker: 1) it predicts resistance to epithelial growth factor receptor (EGFR) inhibitor [25-27], and 2) it is prognostic in patients undergoing liver resection for CLM [28]. Today, there are at least three main reasons to consider RAS mutation assessment as part of the preoperative evaluation of patients with CLM.

First, $R A S$ mutation status has been associated with prognosis in several studies and validated as a prognostic factor in a recent meta-analysis [28]. Brudvik et al. reported a mutation rate of $28 \%$ in 14 studies including 1809 patients. RAS mutations were negatively associated with overall and recurrence free survival, irrespective of anti-EGFR therapy. In this meta-analysis, 10 of 14 studies evaluated KRAS exon 2 (codon 12 and 13) mutations. Due to the rarity of KRAS mutations in exons 3 (codon 61), and exons 4 (codon 146) and NRAS mutations in patients with stage IV colorectal cancer $(<11 \%$ of all patients), the incidence in the selected population of patients resected for CLM is low, and precludes any specific survival analysis. However, recent data on resistance to anti-EGFR treatment suggested that the current standard-of-care panel should be expanded to include additional mutations $[27,29,30]$. Therefore, we recommend an expanded $R A S$ analysis including any $R A S$ mutation as part of the preoperative evaluation, as it represents a major prognostic factor.

Second, KRAS mutations are likely to predict a pattern of clinical presentation and recurrence. Tie et al. reported a higher association of KRAS mutations with lung (62\%) and brain (56\%) metastases than with primary tumors (35\%) [31]. More recently, Perreira et al. confirmed that lung metastases were more likely to develop over time in patients with KRAS mutations [32]. After CLM resection, the impact of KRAS mutations on recurrence pattern remains unclear. Margonis et al. reported no impact of KRAS mutations on recurrence patterns [33] after a median follow-up of 28 months. However, with a longer median follow up of 33 months, our group reported a higher rate of early lung recurrence for patients with KRAS mutations [34]. Taken together, these data suggest that KRAS mutations are associated with organ site specific recurrence patterns that may be relevant to the evaluation and follow-up of patients resected for CLM.

Third, the evaluation of $R A S$ mutations represents a valuable and stable tool to determine long-term outcome after CLM resection. RAS status can be evaluated on a simple biopsy either from the primary tumor at endoscopy, or from a liver biopsy. With there being more than a 90 percent concordance rate between colorectal primary tumors and their metastases regarding RAS status [35-37] and the stability of RAS status over time, even after chemotherapy [38], it allows for an easy and early determination of tumor biology. Currently, prognostic indicators after CLM resection are represented by clinicopathological scores [39-42] and the response to chemotherapy evaluated radiologically [43, 44] or pathologically $[45,46]$. Clinicopathological score related to metastases and primary tumor (e.g., sizes of CLM, number of CLM, primary positive node, and carcinoembryonic antigen level) fluctuate during the course of treatment with different scores pre- and post-chemotherapy. Evaluation of the preoperative response either radiologically or pathologically depends on the interpretation, and this may vary overtime. Recently, our group reported that $R A S$ mutational status was correlated with radiological and pathological response and could be used as a 
surrogate marker of response for patients undergoing evaluation of CLM prior to resection [47]. Therefore, $R A S$ status appears clinically most appropriate to evaluate tumor biology during the course of disease.

The future of cancer care is in individualized targeted treatment widely based on the biological status of the tumor. For CLM, RAS status is needed to guide the use of targeted chemotherapy and anti-EGFR $[26,48]$, and it represents a major prognostic factor that could potentially guide the surgical strategy. The decision to operate on patients with advanced CLM is sometimes difficult. For patients with extensive disease, $R A S$ mutations status might encourage aggressive surgery for patients with wild type status or conversely, the consideration of palliative chemotherapy for patients with RAS mutated tumors.

\section{The Role of Intra-Arterial Chemotherapy}

Since liver metastases derive most of their blood supply from the hepatic artery and normal liver tissue is primarily perfused by the portal vein, HAIC has been developed to ensure a greater locoregional concentration of cytotoxic agents. In a recent retrospective study, the histological response after preoperative chemotherapy based on an oxaliplatin regimen administered either intravenously or via the hepatic artery were compared [49]. This study confirmed that complete pathological response (CPR) was significantly higher in patients who received HAIC of oxaliplatin compared to those who did not (33\% versus $10 \%$, respectively. $\mathrm{p}=0.03$ ), and arterial infusion was the only predictor of CPR in multivariate analysis. In patients with unresectable CLM, the rate of secondary resection is correlated to the response rate (RR) [50]. Thus, the higher the RR, the greater the expected resection rate.

Fluorodeoxyuridine is mainly used for HAIC because of its short half-life ( $<10$ minutes) and extensive first-pass extraction by the liver (94-99\%) [51]. However, its biliary relatedtoxicity could limit its administration. The alternative is the use of intra-arterial administration of newer developed molecules. In this field, HAIC with oxaliplatin has had the most important development. Regarding hepatic toxicity, severe oxaliplatin-related lesions defined as the presence of grade 2 and 3 SOS and/or NRH, occurred more frequently in patients who received HAIC with oxaliplatin compared to those treated intravenously, $66 \%$ versus $20 \%$ respectively $(\mathrm{p}<0.001)$ [49].

HAIC is considered technically more demanding than systemic chemotherapy and is reserved for selected patients with high risk of hepatic recurrence. Among the poor prognostic factors identified, the number of CLM is the most widely accepted factor, and is included in the majority of prognostic scores validated to date. In these scores, the risk of hepatic recurrence increases significantly when the number of resected CLM is four or higher. We recently reported the results of a retrospective analysis of 98 patients at high risk of hepatic recurrence $(\geq 4$ resected CLM) treated postoperatively with HAIC containing oxaliplatin plus systemic 5 -FU $(n=44)$ or with modern systemic chemotherapy (FOLFOX or FOLFIRI) ( $n=54)$ [52]. Adjuvant oxaliplatin-based HAIC was feasible with more than four cycles of treatment in $84 \%$ of the patients (average, 8 \pm 1.7 ). Three-year hepatic DFS was significantly longer in patients who received HAIC compared to those who did not ( $49 \%$ versus $21 \%$, respectively. $\mathrm{p}=0.0008$ ) as was the 3 -year DFS (33\% versus $5 \%$, respectively. $\mathrm{p}<0.0001)$. In multivariate analysis, adjuvant HAIC and R0 resection margin status were the only independent prognostic factors for prolonged DFS. This study confirmed that HAIC with oxaliplatin is feasible, and significantly improves DFS in patients at high risk of hepatic recurrence after resection and/or thermal ablation of CLM. The observed DFS benefit is sufficiently substantial to challenge the current standard of treatment and to warrant confirmation in a randomized trial targeting patients 
selected with a high risk of hepatic recurrence. A randomized phase 2 study (CinicalTrials. gov, NCT02494973) has just opened to accrual in France to evaluate the potential survival benefit of adjuvant HAIC with oxaliplatin after resection of at least four CLM.

In conclusion, HAIC increases the rate of both objective and CPR. It allows for the conversion of unresectable to resectable liver metastases. In the adjuvant setting, arterial infusion may be beneficial, especially in patients at high risk of hepatic recurrence, and this approach is being evaluated in a randomized study. As such, HAIC deserves consideration as a new strategy in combination with systemic therapy as part of first line treatment in patients with unresectable liver metastases and in the adjuvant setting in resectable patients at high risk of recurrence.

\section{Conflicts of Interest}

The authors declare no conflict of interest.

\section{References}

1 Manfredi S, Lepage C, Hatem C, Coatmeur O, Faivre J, Bouvier AM: Epidemiology and management of liver metastases from colorectal cancer. Ann Surg 2006;244:254-259.

2 Kopetz S, Chang GJ, Overman MJ, Eng C, Sargent DJ, Larson DW, Grothey A, Vauthey JN, Nagorney DM, McWilliams RR: Improved survival in metastatic colorectal cancer is associated with adoption of hepatic resection and improved chemotherapy. J Clin Oncol 2009;27:3677-3683.

3 Cucchetti A, Ferrero A, Cescon M, Donadon M, Russolillo N, Ercolani G, Stacchini G, Mazzotti F, Torzilli G, Pinna AD: Cure model survival analysis after hepatic resection for colorectal liver metastases. Ann Surg Oncol 2015;22:1908-1914.

4 Shindoh J, Truty MJ, Aloia TA, Curley SA, Zimmitti G, Huang SY, Mahvash A, Gupta S, Wallace MJ, Vauthey JN: Kinetic growth rate after portal vein embolization predicts posthepatectomy outcomes: toward zero liver-related mortality in patients with colorectal liver metastases and small future liver remnant. J Am Coll Surg 2013;216:201-209.

5 Nordlinger B, Sorbye H, Glimelius B, Poston GJ, Schlag PM, Rougier P, Bechstein WO, Primrose JN, Walpole ET, Finch-Jones M, Jaeck D, Mirza D, Parks RW, Collette L, Praet M, Bethe U, Van Cutsem E, Scheithauer W, Gruenberger T, EORTC Gastro-Intestinal Tract Cancer Group Cancer Research UK Arbeitsgruppe Lebermetastasen und-tumoren in der Chirurgischen Arbeitsgemeinschaft Onkologie (ALM-CAO) Australasian Gastro-Intestinal Trials Group (AGITG) Fédération Francophone de Cancérologie Digestive (FFCD): Perioperative chemotherapy with FOLFOX4 and surgery versus surgery alone for resectable liver metastases from colorectal cancer (EORTC Intergroup trial 40983): a randomised controlled trial. Lancet 2008;371:1007-1016.

6 Karoui M, Penna C, Amin-Hashem M, Mitry E, Benoist S, Franc B, Rougier P, Nordlinger B: Influence of preoperative chemotherapy on the risk of major hepatectomy for colorectal liver metastases. Ann Surg 2006;243:1-7.

7 Rubbia-Brandt L, Audard V, Sartoretti P, Roth AD, Brezault C, Le Charpentier M, Dousset B, Morel P, Soubrane 0 , Chaussade S, Mentha G, Terris B: Severe hepatic sinusoidal obstruction associated with oxaliplatin-based chemotherapy in patients with metastatic colorectal cancer. Ann Oncol 2004;15:460-466.

8 Soubrane 0, Brouquet A, Zalinski S, Terris B, Brézault C, Mallet V, Goldwasser F, Scatton O: Predicting high grade lesions of sinusoidal obstruction syndrome related to oxaliplatin-based chemotherapy for colorectal liver metastases: correlation with post-hepatectomy outcome. Ann Surg 2010;251:454-460.

9 Overman MJ, Maru DM, Charnsangavej C, Loyer EM, Wang H, Pathak P, Eng C, Hoff PM, Vauthey JN, Wolff RA, Kopetz S: Oxaliplatin-mediated increase in spleen size as a biomarker for the development of hepatic sinusoidal injury. J Clin Oncol 2010;28:2549-2555.

10 Vauthey JN, Pawlik TM, Ribero D, Wu TT, Zorzi D, Hoff PM, Xiong HQ, Eng C, Lauwers GY, Mino-Kenudson M, Risio M, Muratore A, Capussotti L, Curley SA, Abdalla EK: Chemotherapy regimen predicts steatohepatitis and an increase in 90-day mortality after surgery for hepatic colorectal metastases. J Clin Oncol 2006;24:2065-2072.

11 Folprecht G, Gruenberger T, Bechstein WO, Raab HR, Lordick F, Hartmann JT, Lang H, Frilling A, Stoehlmacher J, Weitz J, Konopke R, Stroszczynski C, Liersch T, Ockert D, Herrmann T, Goekkurt E, Parisi F, Köhne $\mathrm{CH}$ : Tumour response and secondary resectability of colorectal liver metastases following neoadjuvant chemotherapy with cetuximab: the CELIM randomised phase 2 trial. Lancet Oncol 2010;11:38-47. 
12 Garufi C, Torsello A, Tumolo S, Ettorre GM, Zeuli M, Campanella C, Vennarecci G, Mottolese M, Sperduti I, Cognetti F: Cetuximab plus chronomodulated irinotecan, 5-fluorouracil, leucovorin and oxaliplatin as neoadjuvant chemotherapy in colorectal liver metastases: POCHER trial. Br J Cancer 2010;103:1542-1547.

13 Dupré A, Hitier M, Peyrat P, Chen Y, Meeus P, Rivoire M: Associating portal embolization and artery ligation to induce rapid liver regeneration in staged hepatectomy. Br J Surg 2015;102:1541-1550.

14 Schnitzbauer AA, Lang SA, Goessmann H, Nadalin S, Baumgart J, Farkas SA, Fichtner-Feigl S, Lorf T, Goralcyk A, Hörbelt R, Kroemer A, Loss M, Rümmele P, Scherer MN, Padberg W, Königsrainer A, Lang H, Obed A, Schlitt HJ: Right portal vein ligation combined with in situ splitting induces rapid left lateral liver lobe hypertrophy enabling 2-staged extended right hepatic resection in small-for-size settings. Ann Surg 2012;255:405-414.

15 Viganò L, Costa G, Procopio F, Donadon M, Cimino M, Del Fabbro D, Gatti A, Torzilli G: Parenchyma-Sparing Liver Surgery for Large Segment 1 Tumors: Ultrasound-Guided Lateral and Superior Approaches as Safe Alternatives to Major Hepatectomy. J Am Coll Surg 2015;221:e65-e73.

16 Adam R, Pascal G, Castaing D, Azoulay D, Delvart V, Paule B, Levi F, Bismuth H: Tumor progression while on chemotherapy: a contraindication to liver resection for multiple colorectal metastases? Ann Surg 2004;240:1052-1061, discussion 1061-1064.

17 Giuliante F, Ardito F, Ferrero A, Aldrighetti L, Ercolani G, Grande G, Ratti F, Giovannini I, Federico B, Pinna AD, Capussotti L, Nuzzo G: Tumor progression during preoperative chemotherapy predicts failure to complete 2-stage hepatectomy for colorectal liver metastases: results of an Italian multicenter analysis of 130 patients. J Am Coll Surg 2014;219:285-294.

18 Cauchy F, Aussilhou B, Dokmak S, Fuks D, Gaujoux S, Farges O, Faivre S, Lepillé D, Belghiti J: Reappraisal of the risks and benefits of major liver resection in patients with initially unresectable colorectal liver metastases. Ann Surg 2012;256:746-752, discussion 752-754.

19 Shindoh J, Tzeng CW, Aloia TA, Curley SA, Zimmitti G, Wei SH, Huang SY, Gupta S, Wallace MJ, Vauthey JN: Portal vein embolization improves rate of resection of extensive colorectal liver metastases without worsening survival. Br J Surg 2013;100:1777-1783.

20 Falcone A, Ricci S, Brunetti I, Pfanner E, Allegrini G, Barbara C, Crinò L, Benedetti G, Evangelista W, Fanchini L, Cortesi E, Picone V, Vitello S, Chiara S, Granetto C, Porcile G, Fioretto L, Orlandini C, Andreuccetti M, Masi G, Gruppo Oncologico Nord Ovest: Phase III trial of infusional fluorouracil, leucovorin, oxaliplatin, and irinotecan (FOLFOXIRI) compared with infusional fluorouracil, leucovorin, and irinotecan (FOLFIRI) as first-line treatment for metastatic colorectal cancer: the Gruppo Oncologico Nord Ovest. J Clin Oncol 2007;25:1670-1676.

21 Adam R, Wicherts DA, de Haas RJ, Ciacio O, Lévi F, Paule B, Ducreux M, Azoulay D, Bismuth H, Castaing D: Patients with initially unresectable colorectal liver metastases: is there a possibility of cure? J Clin Oncol 2009;27:1829-1835

22 Lam VW, Spiro C, Laurence JM, Johnston E, Hollands MJ, Pleass HC, Richardson AJ: A systematic review of clinical response and survival outcomes of downsizing systemic chemotherapy and rescue liver surgery in patients with initially unresectable colorectal liver metastases. Ann Surg Oncol 2012;19:1292-1301.

23 Sadot E, Groot Koerkamp B, Leal JN, et al: Resection margin and survival in 2368 patients undergoing hepatic resection for metastatic colorectal cancer: surgical technique or biologic surrogate? Ann Surg 2015;262:476-485; discussion 483-485.

24 Andreou A, Aloia TA, Brouquet A, Dickson PV, Zimmitti G, Maru DM, Kopetz S, Loyer EM, Curley SA, Abdalla EK, Vauthey JN: Margin status remains an important determinant of survival after surgical resection of colorectal liver metastases in the era of modern chemotherapy. Ann Surg 2013;257:1079-1088.

25 Amado RG, Wolf M, Peeters M, Van Cutsem E, Siena S, Freeman DJ, Juan T, Sikorski R, Suggs S, Radinsky R, Patterson SD, Chang DD: Wild-type KRAS is required for panitumumab efficacy in patients with metastatic colorectal cancer. J Clin Oncol 2008;26:1626-1634.

26 Van Cutsem E, Köhne CH, Hitre E, Zaluski J, Chang Chien CR, Makhson A, D’Haens G, Pintér T, Lim R, Bodoky G, Roh JK, Folprecht G, Ruff P, Stroh C, Tejpar S, Schlichting M, Nippgen J, Rougier P: Cetuximab and chemotherapy as initial treatment for metastatic colorectal cancer. N Engl J Med 2009;360:1408-1417.

27 Douillard JY, Oliner KS, Siena S, Tabernero J, Burkes R, Barugel M, Humblet Y, Bodoky G, Cunningham D, Jassem J, Rivera F, Kocákova I, Ruff P, Błasińska-Morawiec M, Smakal M, Canon JL, Rother M, Williams R, Rong A, Wiezorek J, Sidhu R, Patterson SD: Panitumumab-FOLFOX4 treatment and RAS mutations in colorectal cancer. N Engl J Med 2013;369:1023-1034.

28 Brudvik KW, Kopetz SE, Li L, Conrad C, Aloia TA, Vauthey JN: Meta-analysis of KRAS mutations and survival after resection of colorectal liver metastases. Br J Surg 2015;102:1175-1183.

29 Therkildsen C, Bergmann TK, Henrichsen-Schnack T, Ladelund S, Nilbert M: The predictive value of KRAS, NRAS, BRAF, PIK3CA and PTEN for anti-EGFR treatment in metastatic colorectal cancer: A systematic review and meta-analysis. Acta Oncol 2014;53:852-864.

30 Atreya CE, Corcoran RB, Kopetz S: Expanded RAS: refining the patient population. J Clin Oncol 2015;33:682685.

31 Tie J, Lipton L, Desai J, Gibbs P, Jorissen RN, Christie M, Drummond KJ, Thomson BN, Usatoff V, Evans PM, Pick AW, Knight S, Carne PW, Berry R, Polglase A, McMurrick P, Zhao Q, Busam D, Strausberg RL, Domingo E, Tomlinson IP, Midgley R, Kerr D, Sieber OM: KRAS mutation is associated with lung metastasis in patients with curatively resected colorectal cancer. Clin Cancer Res 2011;17:1122-1130.

32 Pereira AA, Rego JF, Morris V, Overman MJ, Eng C, Garrett CR, Boutin AT, Ferrarotto R, Lee M, Jiang ZQ, Hoff PM, Vauthey JN, Vilar E, Maru D, Kopetz S: Association between KRAS mutation and lung metastasis in advanced colorectal cancer. Br J Cancer 2015;112:424-428. 
33 Margonis GA, Spolverato G, Kim Y, Karagkounis G, Choti MA, Pawlik TM: Effect of KRAS Mutation on LongTerm Outcomes of Patients Undergoing Hepatic Resection for Colorectal Liver Metastases. Ann Surg Oncol 2015;22:4158-4165.

34 Vauthey JN, Zimmitti G, Kopetz SE, Shindoh J, Chen SS, Andreou A, Curley SA, Aloia TA, Maru DM: RAS mutation status predicts survival and patterns of recurrence in patients undergoing hepatectomy for colorectal liver metastases. Ann Surg 2013;258:619-626, discussion 626-627.

35 Italiano A, Hostein I, Soubeyran I, Fabas T, Benchimol D, Evrard S, Gugenheim J, Becouarn Y, Brunet R, Fonck M, François E, Saint-Paul MC, Pedeutour F: KRAS and BRAF mutational status in primary colorectal tumors and related metastatic sites: biological and clinical implications. Ann Surg Oncol 2010;17:14291434.

36 Knijn N, Mekenkamp LJ, Klomp M, Vink-Börger ME, Tol J, Teerenstra S, Meijer JW, Tebar M, Riemersma S, van Krieken JH, Punt CJ, Nagtegaal ID: KRAS mutation analysis: a comparison between primary tumours and matched liver metastases in 305 colorectal cancer patients. Br J Cancer 2011;104:1020-1026.

37 Vakiani E, Janakiraman M, Shen R, Sinha R, Zeng Z, Shia J, Cercek A, Kemeny N, D’Angelica M, Viale A, Heguy A, Paty P, Chan TA, Saltz LB, Weiser M, Solit DB: Comparative genomic analysis of primary versus metastatic colorectal carcinomas. J Clin Oncol 2012;30:2956-2962.

38 Kawamoto Y, Tsuchihara K, Yoshino T, Ogasawara N, Kojima M, Takahashi M, Ochiai A, Bando H, Fuse N, Tahara M, Doi T, Esumi H, Komatsu Y, Ohtsu A: KRAS mutations in primary tumours and post-FOLFOX metastatic lesions in cases of colorectal cancer. Br J Cancer 2012;107:340-344.

39 Nordlinger B, Guiguet M, Vaillant JC, Balladur P, Boudjema K, Bachellier P, Jaeck D, Association Française de Chirurgie: Surgical resection of colorectal carcinoma metastases to the liver. A prognostic scoring system to improve case selection, based on 1568 patients. Cancer 1996;77:1254-1262.

40 Chi DS, Palayekar MJ, Sonoda Y, Abu-Rustum NR, Awtrey CS, Huh J, Eisenhauer EL, Barakat RR, Kattan MW: Nomogram for survival after primary surgery for bulky stage IIIC ovarian carcinoma. Gynecol Oncol 2008;108:191-194.

41 Iwatsuki S, Dvorchik I, Madariaga JR, Marsh JW, Dodson F, Bonham AC, Geller DA, Gayowski TJ, Fung JJ, Starzl TE: Hepatic resection for metastatic colorectal adenocarcinoma: a proposal of a prognostic scoring system. J Am Coll Surg 1999;189:291-299.

42 Fong Y, Fortner J, Sun RL, Brennan MF, Blumgart LH: Clinical score for predicting recurrence after hepatic resection for metastatic colorectal cancer: analysis of 1001 consecutive cases. Ann Surg 1999;230:309318, discussion 318-321.

43 Shindoh J, Kaseb A, Vauthey JN: Surgical strategy for liver cancers in the era of effective chemotherapy. Liver Cancer 2013;2:47-54.

44 Andreou A, Kopetz S, Maru DM, Chen SS, Zimmitti G, Brouquet A, Shindoh J, Curley SA, Garrett C, Overman MJ, Aloia TA, Vauthey JN: Adjuvant chemotherapy with FOLFOX for primary colorectal cancer is associated with increased somatic gene mutations and inferior survival in patients undergoing hepatectomy for metachronous liver metastases. Ann Surg 2012;256:642-650.

45 Rubbia-Brandt L, Giostra E, Brezault C, Roth AD, Andres A, Audard V, Sartoretti P, Dousset B, Majno PE, Soubrane O, Chaussade S, Mentha G, Terris B: Importance of histological tumor response assessment in predicting the outcome in patients with colorectal liver metastases treated with neo-adjuvant chemotherapy followed by liver surgery. Ann Oncol 2007;18:299-304.

46 Blazer DG 3rd, Kishi Y, Maru DM, Kopetz S, Chun YS, Overman MJ, Fogelman D, Eng C, Chang DZ, Wang H, Zorzi D, Ribero D, Ellis LM, Glover KY, Wolff RA, Curley SA, Abdalla EK, Vauthey JN: Pathologic response to preoperative chemotherapy: a new outcome end point after resection of hepatic colorectal metastases. J Clin Oncol 2008;26:5344-5351.

47 Mise Y, Zimmitti G, Shindoh J, et al: RAS Mutations Predict Radiologic and Pathologic Response in Patients Treated with Chemotherapy Before Resection of Colorectal Liver Metastases. Ann Surg Oncol 2015;22:834-842.

48 Allegra CJ, Jessup JM, Somerfield MR, Hamilton SR, Hammond EH, Hayes DF, McAllister PK, Morton RF, Schilsky RL: American Society of Clinical Oncology provisional clinical opinion: testing for KRAS gene mutations in patients with metastatic colorectal carcinoma to predict response to anti-epidermal growth factor receptor monoclonal antibody therapy. J Clin Oncol 2009;27:2091-2096.

49 Allard MA, Sebagh M, Baillie G, Lemoine A, Dartigues P, Faitot F, Faron M, Boige V, Vitadello F, Vibert E, Elias D, Adam R, Goéré D, Sa Cunha A: Comparison of complete pathologic response and hepatic injuries between hepatic arterial infusion and systemic administration of oxaliplatin in patients with colorectal liver metastases. Ann Surg Oncol 2015;22:1925-1932.

50 Jones RP, Hamann S, Malik HZ, Fenwick SW, Poston GJ, Folprecht G: Defined criteria for resectability improves rates of secondary resection after systemic therapy for liver limited metastatic colorectal cancer. Eur J Cancer 2014;50:1590-1601.

51 Kelly RJ, Kemeny NE, Leonard GD: Current strategies using hepatic arterial infusion chemotherapy for the treatment of colorectal cancer. Clin Colorectal Cancer 2005;5:166-174.

52 Goéré D, Benhaim L, Bonnet S, Malka D, Faron M, Elias D, Lefèvre JH, Deschamps F, Dromain C, Boige V, Dumont F, De Baere T, Ducreux M: Adjuvant chemotherapy after resection of colorectal liver metastases in patients at high risk of hepatic recurrence: a comparative study between hepatic arterial infusion of oxaliplatin and modern systemic chemotherapy. Ann Surg 2013;257:114-120. 